\title{
Inovasi Pembelajaran Kelas Inklusi di SD Negeri 003 Loa Kulu untuk Membentuk Adaptasi Perilaku Sosial Peserta Didik Berkebutuhan Khusus
}

\author{
Suwarni \\ SD Negeri 003 Loa Kulu \\ warni.ponoragan@gmail.com
}

\section{Article History}

accepted 01/12/2020

\begin{abstract}
The function of inclusion school is a platform for children with special needs to receive knowledge and interact with other regular students from various backgrounds. This research was conducted using an exploratory descriptive method towards the development of inclusive schools in SD Negeri 003 Loa Kulu, Kutai Kartanegara Regency. There are 3 parameters discussed that require learning innovation, namely: barriers at the school level, barriers at the class and teacher levels, and the integration of education at the family level and the surrounding environment of the students. At the school level, a skilled and innovative leader is needed. The school principals must have the leadership ability to mobilize teachers and students to be adaptive to find solutions for every problem. This includes finding ways to improves classroom teacher competencies for students with special needs. The result has a big impact on changes in the perceptions of parents and the surrounding environment to support better growth and development for students with special needs. These results can be achieved because of the integration of inclusive school education that involves students' parents as part of the learning system.
\end{abstract}

Keywords: Inclusion school, innovative learning, social behavior

\begin{abstract}
Abstrak
Sekolah inklusi berfungsi sebagai platform bagi anak berkebutuhan khusus menimba ilmu dan berbaur dengan berbagai macam latar belakang dari siswa reguler. Penelitian ini dilakukan dengan metode deskriptif eksploratif terhadap pengembangan sekolah inklusi di SD Negeri 003 Loa Kulu, Kabupaten Kutai Kartanegara. Terdapat 3 parameter yang dibahas yang membutuhkan inovasi pembelajaran, yaitu: permasalahan di level sekolah, permasalahan di level kelas dan guru, dan integrasi pendidikan di level keluarga dan lingkungan sekitar peserta didik. Pada level sekolah, dibutuhkan figur pemimpin yang terampil dan inovatif. Kepala sekolah harus menggunakan metode kepemimpinan yang menggerakkan guru dan siswa untuk solutif dan adaptif terhadap permasalahan yang muncul. Dalam hal ini termasuk menemukan cara mengembangkan kompetensi guru kelas bagi siswa Anak Berkebutuhan Khusus (ABK). Hasil yang berdampak besar adalah berubahnya persepsi orang tua dan lingkungan sekitar juga berubah untuk mendukung tumbuh kembang yang lebih baik bagi siswa ABK. Hasil tersebut dapat tercapai karena integrasi pendidikan sekolah inklusi yang melibatkan orang tua siswa sebagai bagian dari sistem pembelajaran.
\end{abstract}

Kata kunci: Sekolah inklusi, inovasi pembelajaran, perilaku sosial

Social, Humanities, and Education Studies (SHEs): Conference Series p-ISSN 2620-9284 https://jurnal.uns.ac.id/shes 


\section{PENDAHULUAN}

Pendidikan untuk anak berkebutuhan khusus selalu inferior atau bahkan seringkali tidak diperhatikan. Anak-anak dengan disabilitas atau anak berkebutuhan khusus (ABK) dianggap memiliki karakter acuh tak acuh (apatis) dan tidak mampu beradaptasi seperti siswa normal pada umumnya. Miskonsepsi ini tidak hanya terjadi di dunia pendidikan, tetapi hampir di seluruh aspek sosial bermasyarakat.

Secara terminologi, ABK merupakan anak-anak yang memiliki kelainan atau penyimpangan fisik, intelektual, mental, atau sosial yang mempengaruhi perkembangan mental, emosi, atau kondisi fisik (Abdullah, 2013). Keterbatasan tersebut mempengaruhinya dalam melakukan aktivitas sehari-hari, dan seringkali dikucilkan karena keterbatasannya. Kondisi yang termasuk ke dalam ABK antara lain tunarungu (gangguan pendengaran), tunagrahita (gangguan kecerdasan), tunadaksa (kelainan anggota tubuh), tunalaras (gangguan emosi dan perilaku), tunawicara (gangguan bicara), tunaganda (gangguan ketunaan dobel), dan autis.

Selama ini pendidikan untuk ABK masih terpusat di Sekolah Luar Biasa (SLB). Namun, keberadaan SLB yang masih terbatas belum mampu menyediakan pendidikan bagi seluruh siswa ABK. Data dari Badan Pusat Statistik tahun 2017 menunjukkan bahwa hanya sekitar 18\% ABK yang mendapatkan layanan pendidikan (Prodjo, 2020). Selain itu, keluaran hasil pendidikan bagi ABK tidak sepenuhnya untuk akademik dan karakter, melainkan bagaimana siswa ABK mampu beradaptasi dan berinteraksi di lingkungan sosial.

Solusi jangka panjang untuk siswa $\mathrm{ABK}$ adalah dengan mengembangkan kemampuan sosial mereka agar mampu bersosialisasi dengan baik setelah lulus sekolah. Keterbatasan pengetahuan tentang mendidik harus diimbangi dengan pendidikan yang mumpuni di sekolah (Nisa et al., 2018). Stigma negatif terhadap ABK tidak akan mudah untuk dihilangkan jika sistem pendidikan tidak memberikan ruang dan arahan bagi mereka untuk berkembang. Untuk itu diaplikasikan sistem sekolah inklusi karena setiap individu memiliki keunikannya masing-masing yang membuatnya mampu untuk berkembang dengan baik (Qvortrup \& Qvortrup, 2018). Sistem dari sekolah inklusi adalah pencampuran peserta didik reguler dengan peserta didik ABK. Dengan adanya kegiatan belajar bersama dalam satu sekolah, maka terjadi interaksi antara peserta didik reguler dan ABK. Interaksi tersebut mampu meningkatkan pengertian tentang adanya perbedaan dan tentu saja membantu siswa ABK dalam mengembangkan kemampuan sosialnya (Silfiasari, 2017).

Keberadaan sekolah inklusi merupakan salah satu hak setiap manusia untuk mendapatkan pendidikan. Indonesia memiliki Peraturan Menteri Pendidikan Nasional RI Nomor 70 Tahun 2009 tentang pendidikan iklusi yang mengatur tentang sistem sekolah inklusi agar mampu meningkatkan potensi kecerdasan peserta didik. Namun, upaya penyediaan sekolah inklusi yang inklusif terkendala banyak hal, sehingga beberapa daerah bahkan tidak memiliki sekolah inklusi. Padahal, peserta didik ABK sangat membutuhkan, terutama kendala lokasi di mana SLB sangat jauh dari domisili.

Di Kabupaten Kutai Kartanegara, memiliki kesamaan keterbatasan yaitu tidak tersedianya sekolah inklusi. SD Negeri 003 Loa Kulu menjadi salah satu pionir penyelenggara sekolah inklusi sejak tahun 2010 - sekarang dan menjadi satu-satunya sekolah inklusi di wilayah tersebut. Permasalahan yang muncul di sekolah inklusi adalah stigma negatif dari siswa reguler terhadap siswa ABK. Stigma negatif tersebut membuat siswa ABK memiliki perilaku sosial kurang baik karena merasa dilecehkan. Akar permasalahan kemunculan stigma negatif tersebut adalah ketidakmampuan pergaulan dan kurang adaptif yang disebabkan oleh keterbatasan yang dimiliki oleh siswa ABK (Diahwati et al., 2016). Padahal keterampilan pergaulan dapat dilatih asalkan ada dukungan dari kurikulum dan sistem pendidikan yang diaplikasikan (Dulisanti, 2015). 
Untuk itu, dibutuhkan inovasi pembelajaran agar permasalahan tersebut dapat diselesaikan. Pada dasarnya, sistem pembelajaran di SD Negeri 003 Loa Kulu menerapkan kesetaraan bagi peserta didik reguler dan ABK dalam pengajaran, perlakuan, dan bimbingan. Penelitian ini bertujuan untuk mengeksplor inovasi yang dilakukan di SD Negeri 003 Loa dalam membentuk perilaku sosial yang adaptif bagi siswa ABK. Diharapkan akan menjadi best practice dalam pendidikan sekolah inklusi di Indonesia.

\section{METODE}

Penelitian ini dilakukan di SD Negeri 003 Loa Kulu, dengan Nomor Pokok Sekolah Nasional 30404669. Lokasi sekolah berada di Kecamatan Loa Kulu, Kabupaten Kutai Kartanegara, Kalimantan timur.

Penelitian menggunakan metode deskriptif eksploratif untuk menemukan inovasi terhadap masalah utama sekolah inklusi menurut Travers et al. (2014).

1. Permasalahan di level sekolah,

2. Permasalahan di level kelas dan guru, dan

3. Integrasi pendidikan di level keluarga dan lingkungan sekitar anak didik.

Data dikumpulkan melalui metode observasi dan wawancara kepada guru dan peserta didik (ABK). Data dikumpulkan dan dianalisis untuk menjelaskan tentang inovasi pembelajaran yang telah dilakukan. Inovasi pembelajaran tersebut membuahkan hasil yang dibahas dalam pembahasan berikut. Selain itu, penelitian ini juga merupakan sintesis dari pengalaman penulis yang merintis sekolah inklusi di SD Negeri 003 Loa Kulu.

\section{HASIL DAN PEMBAHASAN}

Berikut adalah hasil dan pembahasan tentang inovasi pembelajaran yang dilakukan di SD Negeri 003 Loa Kulu terkait penyelesaian hambatan pendidikan kelas inklusi.

\section{Inovasi Penyelesaian Masalah di Level Sekolah}

Keberadaan sekolah inklusi berhubungan dengan sistem pendidikan sekolah reguler yang selama ini berjalan. Sekolah merupakan mesin utama sistem pendidikan inklusi ini dapat berjalan, dan seringkali permasalahan muncul dalam tahap transisi. Akar utama permasalahannya adalah ketidakmampuan sekolah dalam pengelolaan karena sistem pendidikan inklusi merupakan hal yang baru di Indonesia, yaitu sejak diberlakukannya Peraturan Menteri Pendidikan Nasional Republik Indonesia Nomor 70 Tahun 2009.

Keluarnya Peraturan Menteri tersebut menjadi keharusan setiap pemerintah kabupaten/kota untuk memiliki paling sedikit satu sekolah dasar inklusi. Di tahun yang sama, Kabupaten Kutai Kartanegara dengan luas $27.263 \mathrm{~km}^{2}$ hanya memiliki SLB di ibukota kabupaten. Akses ke SLB tersebut sangat jauh bagi daerah yang terletak jauh dengan ibukota kabupaten, termasuk akses dari Kecamatan Loa Kulu. Inisiasi merintis sekolah inklusi di SD Negeri 003 Loa Kulu tidaklah mudah, karena melewat proses yang cukup panjang untuk mendapat Surat Keputusan dari Kepala Dinas Pendidikan Kabupaten.

Berstatus sebagai sekolah inklusi yang baru, SD Negeri 003 dituntut untuk siap menerima peserta didik ABK dan melakukan kegiatan pembelajaran. Dari sinilah permasalahan tersebut muncul karena sekolah belum siap secara optimal dalam kegiatan tatap muka bagi siswa ABK.

Solusi utama permasalahan ini seperti yang disampaikan oleh Travers et al. (2014) adalah bagaimana sekolah memiliki figur pemimpin, yaitu kepala sekolah, yang terampil 
dan inovatif. Kepemimpinan bagi sekolah inklusi memiliki tugas berat, yaitu untuk mengubah kultur sekolah reguler menjadi sekolah inklusi bagi guru dan siswa, serta menyusun peraturan-peraturan pendukung di level sekolah (administrasi). Solusi yang dilakukan kepala sekolah sebagai penggerak utama sekolah inklusi adalah dengan menggunakan metode kepemimpinan inovasi.

Filosofi inovasi yang dilakukan oleh kepala sekolah adalah dengan memberi ruang bagi guru dan siswa untuk ikut aktif mengembangkan sekolah inklusi, dengan kata lain praktek pendidikan yang adaptif (Putri et al., 2020). Kepala sekolah mengajak peran aktif seluruh elemen di sekolah untuk mengutarakan solusi yang dapat diaplikasikan. Metode tersebut berhasil membuat SD Negeri 003 Loa Kulu menjalankan pembelajaran sekolah inklusi dengan lancar.

\section{Inovasi Penyelesaian Masalah di Level Kelas dan Guru}

Sekolah inklusi pada dasarnya sekolah reguler yang menerima peserta didik $A B K$, sehingga sumber daya manusia di sekolah tidak disiapkan dari awal untuk mengajar siswa ABK. Berbeda seperti SLB, sekolah inklusi mengharuskan guru yang tidak memiliki latar belakang Pendidikan Luar Biasa, dituntut untuk mampu melakukan pembelajaran ke siswa berkebutuhan khusus. Dengan kata lain, guru tidak memiliki kompetensi untuk menjalankan sekolah inklusi dengan baik.

Inovasi untuk meningkatkan kompetensi guru dilakukan dengan mengirim guru SD Negeri 003 Loa Kulu untuk belajar di SLB terdekat. Guru kelas diharuskan untuk mampu menyerap ilmu yang disampaikan oleh guru-guru di SLB, agar dapat diaplikasikan di kelas mereka. Mengirim guru untuk belajar di SLB butuh penerimaan dari guru tersebut untuk belajar hal baru yang tidak mudah. Namun, dengan pengertian bahwa pendidikan inklusi ini penting bagi guru-guru di SD Negeri 003 Loa Kulu, peningkatan kompetensi guru berjalan dengan lancar.

Ujian bagi guru-guru yang telah ditingkatkan kompetensinya adalah adalah bagaimana menemukan cara untuk membentuk karakter siswa ABK menjadi lebih baik. Tidak hanya satu sisi saja, termasuk bagaimana siswa reguler dapat mengerti dan bergaul dengan baik dengan siswa ABK. Siswa ABK seringkali sulit untuk bergaul dengan siswa lainnya. Menyelesaikan permasalahan ini bukanlah hal yang mudah, karena harus mengerti karakter dan sifat masing-masing siswa ABK.

Salah satu inovasi yang dilakukan di SD Negeri 003 Loa Kulu untuk meningkatkan kemampuan siswa ABK dalam berinteraksi dengan murid lainnya, termasuk mendidik karakter mereka, adalah dengan pembiasaan sosial. Hal ini penting dilakukan karena siswa $\mathrm{ABK}$ yang mampu bersosialisasi dan berkumunikasi mendapat respon dan pengakuan positif dari seluruh siswa (Setyawati, 2018). Metode pembiasaan ini untuk melatih siswa ABK berperilaku sosial yang baik, sebagai bagian dari pendidikan yang tidak mereka dapatkan di SLB. Terdapat 5 indikator utama dalam pembiasaan sosial ini, yaitu:

1. Memberi salam dan berkata sopan kepada siapapun (guru dan teman),

2. Menolong teman,

3. Berpakaian yang bersih dan rapi,

4. Membuang sampah pada tempatnya, dan

5. Mengikuti antrean.

Pembiasaan sosial ini dalam prakteknya memberikan bimbingan kepada siswa ABK jika mereka melakukan kegiatan yang tidak baik. Hal ini diikuti dengan pemberian penghargaan kepada siswa jika mereka melakukan hal yang baik sebagai motivasi kepada mereka. Hasilnya, peserta didik ABK terbiasa untuk berkata sopan dalam berinteraksi kepada guru dan teman mereka. Mereka juga mulai terbiasa menolong 
teman baik diminta maupun tidak, termasuk sudah mulai terbiasa berpakaian rapi, mengantri, dan membuang sampah pada tempatnya.

Keberhasilan pembiasaan yang baik oleh peserta didik di sekolah inklusi ini tidak lepas dari semangat guru-guru untuk belajar kembali dan melepas stigma bahwa mereka tidak mampu. Walaupun kapasitas guru dan metode pembelajaran belum sempurna, namun hasil-hasil yang ditunjukkan oleh peserta didik ABK membuahkan hasil positif. Salah satu hasil pembiasaan adalah siswa ABK telah ikut serta dalam piket di kelas dan kemampuannya dalam mengurus diri sendiri tanpa bantuan orang lain. Peningkatan keterampilan dan kemampuan dalam bersosialisasi ini dapat menumbuhkan rasa percaya diri siswa ABK.

Hal ini didukung oleh Prihantoro (2018) yang menyatakan metode pembiasaan membuat $A B K$ mampu beradaptasi di lingkungan sosial yang lebih beragam. Hasil ini bukan tanpa dasar, karena siswa ABK memerlukan interaksi dan kondisi yang sesuai dengan karakteristik dan kemampuannya (Nisa et al., 2018). Inovasi pembiasaan ini menjadi solusi bagi guru sebagai metode pembelajaran yang tepat guna, selain mengajar tentang bahan ajar kognitif. Mengingat kondisi sosial dan interaksi yang baik saat di sekolah mempengaruhi hasil akademik secara signifikan (Pratiwi \& Mangunsong, 2018).

\section{Integrasi Pendidikan di Keluarga dan Lingkungan}

Anak berkebutuhan khusus kurang diperlakukan dengan baik, mengingat kurangnya pengetahuan masyarakat, termasuk keluarganya sendiri. Padahal, lingkungan di mana ABK tinggal, baik di sekolah maupun di rumah sangat dominan mempengaruhi perilaku dan karakter peserta didik ABK (Mambela, 2020).

Kehadiran sekolah inklusi mampu mempengaruhi penerimaan orang tua untuk memahami kondisi anaknya dan resilien terhadap pengaruh negatif dari eksternal (Hidayati, 2011). Kurangnya perhatian orang tua pada dasarnya menjadi permasalahan dalam kesuksesan pendidikan inklusi (Tarnoto, 2016). Penyebabnya tidak lain karena peserta didik menjadi lebih stress dan tidak mampu untuk berkembang dengan baik jika orang tua tidak memberikan dukungan. Peran keluarga ini penting sebagai dukungan sosial baik siswa ABK di luar sekolah yang tidak terlepas dari sistem pendidikan inklusi (Qolina et al., 2017).

Pendidikan inklusi di SD Negeri 003 Loa Kulu telah membantu memperbaiki persepsi orang tua dan lingkungan sekitar tentang bagaimana berinteraksi dengan anak berkebutuhan khusus. Kehadiran siswa reguler yang berinteraksi secara langsung dengan siswa $\mathrm{ABK}$, mendapat pengalaman langsung yang positif. Pengalaman tersebut ditransfer ke orang tua dan lingkungannya, yang secara tidak langsung mengintegrasikan sistem pendidikan inklusi dengan lebih baik. Bukan tidak mungkin di masa mendatang, pendidikan inklusi menjadi hal lazim dan menghilangkan stigma negatif terhadap ABK; yang tidak dapat dilakukan pada pendidikan di SLB.

\section{SIMPULAN}

Sistem pendidikan inklusi di SD Negeri 003 Loa Kulu, sebagai mandat dari Peraturan Menteri Pendidikan Nasional Republik Indonesia Nomor 70 Tahun 2009 telah membuat akses pendidikan bagi siswa ABK terbuka di daerah tersebut. Inovasi-inovasi pembelajaran dilakukan dengan mengintegrasikan pendidikan di sekolah dan di rumah. Guru dan orang tua harus berperan aktif untuk keberhasilan pendidikan dari segi peningkatan perbaikan karakter dan kognitif siswa. Hal yang menjadi garis bawah adalah metode pembiasaan sangatlah berhasil meningkatkan kemampuan bersosialisasi bagi siswa ABK, yang berdampak positif terhadap nilai akademik. Terlebih lagi, persepsi 
orang tua dan lingkungan sekitar juga berubah untuk mendukung tumbuh kembang yang lebih baik bagi siswa ABK.

\section{DAFTAR PUSTAKA}

Abdullah, N. (2013). Mengenal Anak Berkebutuhan Khusus. Magistra, 25(86), 1-10.

Diahwati, R., Hariyono, \& Hanurawan, F. (2016). Keterampilan Sosial Siswa Berkebutuhan Khusus di Sekolah Dasar Inklusi. Jurnal Pendidikan: Teori, Penelitian, Dan Pengembangan, 1(8), 1612-1620.

Dulisanti, R. (2015). Penerimaan Sosial dalam Peoses Pendidikan Inklusif (Studi Kasus pada Proses Pendidikan Inklusif di SMK Negeri 2 Malang). Indonesian Journal of Disability Studies, 2(1), 52-60.

Hidayati, N. (2011). Dukungan Sosial bagi Keluarga Anak Berkebutuhan Khusus. INSAN, 13(1), 12-20.

Mambela, S. (2020). Mainstreaming sebagai Alternatif Penanganan Pendidikan Anak Berkebutuhan Khusus di Indonesia. SOSIOHUMANIKA, 3(2), 295-305.

Nisa, K., Mambela, S., \& Badiah, L. I. (2018). Karakteristik dan Kebutuhan Anak Berkebutuhan Khusus. Abadimas Adi Buana, 2(1), 33-40.

Pratiwi, F. D., \& Mangunsong, F. (2018). Prediktor Pembentukan Konsep Diri Akademik pada Siswa Berkebutuhan Khusus di Sekolah Dasar Inklusif. INQUIRY Jurnal Ilmiah Psikologi, 9(2), 79-90.

Prihantoro, R. A. (2018). Pendidikan karakter anak berkebutuhan khusus melalui gerakan aku istimewa aku indonesia untuk siswa sekolah dasar. Konferensi IImiah Dasar. Tema: Membumikan Pendidikan Karakter Dengan Pendekatan Inklusi, 6167.

Prodjo, W. A. (2020). Sekolah Berkebutuhan Khusus, Ini 6 Jenis SLB yang Harus Kamu Ketahui Halaman all Kompas.com. https://edukasi.kompas.com/read/2020/01/20/22101771/sekolah-berkebutuhankhusus-ini-6-jenis-slb-yang-harus-kamu-ketahui?page=all

Putri, Z. F., Miarakhman, N. F., \& Krisnawati, R. D. (2020). Strategi Kepemimpinan Kepala Sekolah dalam Implementasi Kebijakan Pendidikan Inklusif di SMP Negeri 2 Yogyakarta. Khazanah Intelektua, 4(3), 932-953.

Qolina, E., Hamid, A. Y. S., \& Wardani, I. Y. (2017). Pengaruh Psikoedukasi Keluarga Terhadap Ansietas Dan Depresi Keluarga Yang Mempunyai Anak Dengan Autis Di Sekolah Khusus Autis Harapan Utama Ananda Depok. Jurnal JKFT, 2(2), 97.

Qvortrup, A., \& Qvortrup, L. (2018). Inclusion: Dimensions of inclusion in education. In International Journal of Inclusive Education (Vol. 22, Issue 7, pp. 803-817). Routledge.

Setyawati, R. (2018). Pendidikan Inklusi: Penerimaan Siswa Terhadap Perilaku Sosial dan Emosi Anak Berkebutuhan Khusus pada SMP Negeri 2 Sewon dan SMP Muhammadiyah 1 Bambanglipuro di Kabupaten Bantul. G-COUNS: Jurnal Bimbingan Dan Konseling, 3(1), 84-91.

Silfiasari, S. (2017). Empati dan Pemaafan daman Hubungan Pertemanan Siswa Regular Kepada Siswa Berkebutuhan Khusus (ABK) di Sekolah Inklusif. Jurnal IImiah Psikologi Terapan, 5(1), 126-143.

Tarnoto, N. (2016). Permasalahan-Permasalahan yang Dihadapi Sekolah Penyelenggara Pendidikan Inklusi pada Tingkat SD. Humanitas, 13(1), 50-61.

Travers, J., Balfe, T., Butler, C., Day, T., Dupont, M., McDaid, R., O’Donnel, M., \& Prunty, A. (2014). Addressing the Challenges and Barriers to Inclusion in Irish Schools. Special Education Department, St Patrick's College. 